\title{
Estudo sobre a eventual utilidade de raios gama na profilaxia da malária transmissível por transfusão de sangue
}

\author{
A study on the fortuitons advantage of gamma irradiation in \\ the prophylaxis of transmissible malaria \\ by blood transfusion
}

\author{
Lúcia Maria Almeida Braz, Vicente Amato Neto, Fábio Luís Carignani, \\ Andréia O taviani Di Pietro Fernandes, Nelson Hamerschlak, \\ Laura Santoro Zuanella, Maria de Fátima dos Santos Silva, \\ Iolanda Lima de Souza e Massayuki O kumura
}

\begin{abstract}
Resumo $O$ estudo foi realizado com o objetivo de avaliar a eventual utilidade de raios gama na profilaxia da malária transmissível por transfusão de sangue, tendo sido, para isso, usados camundongos infectados pelo Plasmodium berghei. Na primeira fase, quando submetemos sangue deles retirado a 2.500 e 5.000rad, com associação ou não de metronidazol, não obtivemos sucesso, já que todos os animais antes sem a parasitose apresentaram parasitemia e morreram após inoculação do sangue irradiado. Porém, ocorreu êxito parcial na segunda fase, ao serem empregados 10.000 e 15.000 rad, porquanto $20 \%$ e $40 \%$ dos roedores, respectivamente, embora tenham ficado infectados, sobreviveram, com posterior negativação quanto à presença do P. berghei.
\end{abstract}

Palavras-chaves: Transfusão de sangue. Profilaxia da malária. Raios gama. Plasmodium berghei.

\begin{abstract}
This study was carried out to evaluate the fortuitons advantage of using gamma irradiation in the prophylaxis of transmissible malaria by blood transfusion, with mice as the experimental model. In the first step, when the infected blood with Plasmodium berghei was submitted to 2,500rad and 5,000rad, with or without metronidazol, there was no success, because the animals presented parasitaemia and died after inoculation of irradiated blood. However, there was partial success in the second step, when the infected blood received 10,000 and 15,000rad, and was inoculated in mice, which showed infection, and presented a survival rate of $20 \%$ and $40 \%$, respectively, with later negativation of blood infected by P. berghei.
\end{abstract} Key-words: Blood transfusion. Malaria prophylaxis. Gamma irradiation. Plasmodium berghei.

\footnotetext{
Laboratório de Investigação Médica - Parasitologia do Hospital das Clínicas, da Faculdade de Medicina da Universidade de São Paulo, São Paulo, SP, Brasil.

Endereço para correspondência: Lúcia Maria Almeida Braz. Laboratório de Investigação Médica-Parasitologia. Av. Dr. Enéas de Carvalho Aguiar 500, 05403-000 São Paulo, SP, Brasil.

Fax: (011) 852-3622

E-mail: Imabraz@usp.br

Recebido para publicação em 09/02/98.
} 
Acredita-se que malária decorrente da hemoterapia, em países nos quais a parasitose é endêmica, ocorre segundo cifras que estão entre 30 a 60 acometimentos por milhão de unidades transfundidas. Em setores nãoendêmicos a freqüência corresponde a cerca de 0,2 casos por milhão e, neles, cuidados têm sido adotados no sentido de selecionar doadores provenientes de áreas onde a doença é transmitida da maneira habitual, através de anofelinos 4 .

A malária transfusional é primordialmente derivada de hemácias parasitadas, mas pode depender até mesmo de pequenos concentrados de sangue mantidos por longo tempo em geladeira ${ }^{9}$, quando presente o plasmódio.

Nas regiões não-endêmicas a prevenção em geral é baseada na seleção adequada de doadores e, eventualmente, por meio de provas sorológicas pertinentes a indivíduos migrantes 5 . Nas endêmicas o problema, contudo, afigura-se muito maior. A anamnese pode afastar potenciais doadores infectados e o exame microscópico direto é extremamente trabalhoso; além disso, depende do cuidado e do período de tempo em que uma lâmina é analisada, devendo acrescentarse a isso a pequena sensibilidade. Os testes sorológicos são de pouca utilidade pois excluem grande parte dos que comparecem à doação. Por seu turno, a quimioprofilaxia esbarra no óbice representado pelos fármacos empregados, eficientes ou não, tendo inclusive a chance de causar efeitos adversos 4 .

É lícito reconhecer que, presentemente, não podemos interpretar como ideal a triagem de doadores para a prevenção da malária. Interrogatório e testes sorológicos não satisfazem totalmente e daí advém a conveniência de buscar outros meios, exemplificados pela atuação de agentes físicos e químicos no sangue, mormente em regiões nas quais há maior perigo de transmissão decorrente de hemoterapia.

O metronidazol é droga utilizada rotineiramente na espécie humana com muito pouca toxicidade e sabe-se que determinados fármacos são capazes de potencializar a lesão da irradiação ionizante em células 16 .

Diante do exposto, torna-se altamente desejável contar com algum tipo de conduta apta a possibilitar maior segurança em transfusões, constituindo avanço em comparação com as medidas comumente propostas. A propósito, lembramos que a atividade da violeta de genciana já foi avaliada e demonstrou real efetividade em estudos realizados em camundongos 28.

A irradiação do sangue e de seus componentes é prática quase que rotineira em Serviços de hemoterapia, para prevenção da doença de enxerto no hospedeiro e, também, nas transfusões executadas em pacientes imunocomprometidos. Existem dispositivos de alta segurança e fácil manipulação integráveis aos equipamentos costumeiramente usados nos trabalhos hemoterápicos.

A ação de raios gama sobre formas sanguícolas do Trypanosoma cruzi ficou demonstrada; porém, as quantidades extremamente altas necessárias para ser conseguido o objetivo profilático impedem preconização, em virtude de danos celulares ocasionáveis?.

Com a pesquisa agora relatada procuramos verificar se 2.500 e $5.000 \mathrm{rad}$, associados ou não ao metronidazol, e se 10.000 e $15.000 \mathrm{rad}$ impedem a infecção pelo Plasmodium berghei, procurando colaborar quanto à prevenção da veiculação transfusional de plasmódios.

\section{MATERIAL E MÉTODOS}

Inicialmente infectamos, pela via intraperitoneal, 60 camundongos Balb/C, com 0,Iml de sangue contendo 106 formas de P. berghei. Decorridos sete dias sacrificamos os animais para obter, por punção cardíaca, aproximadamente $30 \mathrm{ml}$ de sangue parasitado. Outrossim, sacrificamos 40 camundongos não infectados para retirar $25 \mathrm{ml}$ de sangue. Colocamos os sangues, de infectados ou não, em tubos de ensaio contendo $0,7 \mathrm{ml}$ do anticoagulante CPDA (citrato; fosfato; dextrose; adenina), a fim de irradiá-los ou não com raios gama, tendo como fonte o césio 137 . Em prosseguimento, inoculamos intraperitonealmente $0,5 \mathrm{ml}$ em cada animal dos seguintes Grupos de dez: I - sangue infectado e irradiado com 2.500rad; II - sangue infectado e irradiado com 5.000rad; III - sangue infectado e não irradiado; IV - sangue não infectado e irradiado com 2.500rad; $V$ - sangue não infectado e irradiado com 5.000rad; VI - sangue não infectado e não irradiado; VII - sangue infectado e irradiado com 2.500rad, estando adicionados $10 \mathrm{mg}$ de metronidazol; VIII - sangue infectado e irradiado com 5.000rad, estando adicionados $10 \mathrm{mg}$ de metronidazol; IX - sangue infectado e não irradiado, estando adicionados $10 \mathrm{mg}$ de metronidazol; $X$ - sangue não infectado e não irradiado, estando adicionados $10 \mathrm{mg}$ de 
metronidazol; XI - sangue não infectado e irradiado com 5.000rad, estando adicionados $10 \mathrm{mg}$ de metronidazol; complementarmente, infectamos pela via intraperitoneal 33 camundongos Swiss com 106 formas de $P$. berghei. Depois de uma semana sacrificamos os animais e obtivemos, através de punção cardíaca, $15 \mathrm{ml}$ de sangue, de roedores infectados, além de $10 \mathrm{ml}$ de outros sem a parasitose, sendo parte do sangue submetido à radiação com césio 137. Uma hora posteriormente à irradiação dos tubos, com $5 \mathrm{ml}$ de sangue com CPDA, contaminado ou não, injetamos $0,4 \mathrm{ml}$ em cada animal de cinco Grupos com dez componentes, de acordo com as especificações adiante expostas: I - sangue infectado e irradiado com 10.000rad; II - sangue infectado e irradiado com 15.000rad; III - sangue infectado e não irradiado; IV - sangue não infectado e irradiado com 15.000rad; V - sangue não irradiado e não infectado.

Em todos os grupos avaliamos a existência de parasitemia em dias alternados, desde o segundo dia posterior à infecção, através de esfregaços de sangue em lâminas e coloração pelo método de Giemsa. Parte dos animais sobreviventes foi sacrificada após 120 dias da infecção e, outra, imunodeprimida após 120 dias, durante 70 dias, em dias alternados, com ciclosporina e prednisona, por via oral, conforme as doses, respectivamente, de $5 \mathrm{mg} / \mathrm{ml} \mathrm{e}$ $0,2 \mathrm{mg} / \mathrm{ml}$, em $0,4 \mathrm{ml}$ de volume, para cada um dos camundongos. Ocorreu sacrifício destes animais 300 dias após a infecção e 110 dias depois do término da imunodepressão. Ao final, efetuamos exames histopatológicos.

Quando sacrificados os sobreviventes, colocamos fígado e baço em formol a 10\% para análises subseqüentes às aplicações dos processos da hematoxilina-eosina e de Perls. Os órgãos provieram de um animal dos grupos I e II, além de quatro camundongos imunodeprimidos; o sacrifício daqueles aconteceu 120 dias depois da infecção e, a respeito destes tal período foi de 300.

Para as irradiações empregamos bomba de césio ("Atomic Energy"- Canadá), apropriada para Serviços de hemoterapia.

\section{RESULTADOS}

Na primeira etapa a parasitemia já era perceptível no segundo dia em todos os animais dos grupos I, II, III, VII, VIII e IX, com total mortalidade antes do vigésimo dia.

Quanto à segunda fase, registramos positividade nos componentes dos grupos I, II e III; neste, a parasitemia, de 100\% (10/10), existia dois dias depois da inoculação, enquanto que nos I e II as taxas situaram-se em 60\% (6/10).

Decorridos 16 dias, nos grupos I, II e III a positividade atingiu $100 \%$ conforme mostra a Tabela 1, com total mortalidade do grupo III no vigésimo dia, todavia, verificamos cifras de $30 \%$ (3/10) no grupo I e de $20 \%(2 / 10)$ no grupo II.

Após 75 dias, 20\% (2/10) dos animais do grupo I e 40\% (4/10) do grupo II permaneceram vivos, sendo que, quanto à parasitemia, um animal do grupo I já estava negativo desde o 24ำ dia e o outro apenas no 93; do grupo II, três já estavam negativos desde o $18^{\circ}$ dia e um no 74\%.

Nos exames histopatológicos de fígado e baço não encontramos plasmódios, mas sim pigmento malárico, sempre em maior quantidade se houve imunodepressão.

Tabela 1 - Número de mortes, em dias, nos cinco grupos, após a inoculação do Plasmodium berghei.

\begin{tabular}{|c|c|c|c|c|c|c|c|c|c|c|}
\hline \multirow[t]{2}{*}{ Grupo } & \multirow[t]{2}{*}{ Número de animais em cada grupo } & \multicolumn{8}{|c|}{ Número de mortes } & \multirow[t]{2}{*}{ Mortalidades até 75 dias (\%) } \\
\hline & & $6^{\circ}$ & $14^{\circ}$ & $16^{\circ}$ & $18^{\circ}$ & $20^{\circ}$ & $22^{\circ}$ & $26^{\circ}$ & $74^{\circ}$ & \\
\hline I & 10 & & & & 3 & & 1 & 3 & 1 & 80 \\
\hline II & 10 & & 1 & & & 1 & 1 & 2 & 1 & 60 \\
\hline III & 10 & 2 & 2 & 3 & 2 & 1 & & & & 100 \\
\hline IV & 10 & & & & & & & & & 0 \\
\hline $\mathrm{V}$ & 10 & & & & & & & & & 0 \\
\hline
\end{tabular}

\section{DISCUSSÃO}

$\mathrm{Na}$ primeira parte, a ação dos raios gama sobre o $P$. berghei, em quantidades toleráveis de 2.500 e 5.000rad, com ou sem metronidazol, não foi eficaz, tendo sido detectada parasitemia no terceiro dia, além de morte de $100 \%$ dos animais, de todos os grupos, no vigésimo. 
Também não obteve sucesso a utilização de 2.500 e 5.000rad para prevenir a infecção transfusional pelo $T$. cruzi1.

O conhecimento de que a infecção devida ao $P$. berghei em camundongos e ratos jovens evolui de maneira fulminante e fatal3, não se coadunou com o constatado na totalidade dos animais nos grupos I e II, da segunda fase, após exposição do sangue à irradiação por meio de 10.000 e 15.000 rad.

De cada um dos dois conjuntos de dez animais que receberam sangue após irradiação com 10.000 e 15.000 rad foi impedida a morte de dois e quatro, respectivamente, diminuindo então a porcentagem citada para $80 \%$ e $60 \%$ (Tabela 1).

No Grupo controle, independentemente de irradiação, a mortalidade correspondeu a $100 \%$, no vigésimo dia da infecção.

Plasmódios não foram vistos nos exames histopatológicos, provavelmente como decorrência da atividade antiparasitária, e a presença do pigmento malárico indica que infecção existiu.

Rememoramos que a efetiva ação sucedeu quando avaliada a atividade de 200 e $300 \mathrm{krad}$ sobre o T. cruzi, tornando o sangue inócuo quanto à capacidade de produzir infecção nos animais 7 .
A análise dos resultados que obtivemos permite supor como parcial a capacidade dos raios gama no sentido de inativar o plasmódio quando aplicados 10.000 e 15.000rad, porquanto nos animais inoculados com sangue contendo o parasita a sobrevida foi maior, em comparação ao registrado quando não houve irradiação. Porém, a respeito da mencionada ação incompleta impõe-se destacar que 10.000 e 15.000rad estão acima do tolerável, podendo ser prejudiciais às células sanguíneas, de molde a restringir utilização hemoterápica.

A despeito de não termos obtido sucesso quanto à possibilidade de aplicar com segurança, em sentido prático, a proposição escolhida, cremos que se afiguram válidos a incitação para a procura de novos processos preventivos, a exemplificação de metodologia imitável e o registro do que se pode esperar dos raios gama, conforme o que realizamos, sem dúvida útil para cooperar com interessados na mesma linha de especulações.

\section{AGRADECIMENTOS}

Para Carla Pagliari, Jacob Rosenblit, Maria Antonieta Longo Galvão Silva e Maria Irma Seixas Duarte pelas colaborações prestadas.

\section{REFERÊNCIAS BIBLIOGRÁFICAS}

1. Amato Neto V, Pasternak J, Matsubara L, Hamerschlak N, Carignani FL. Tentativas de uso de raios gama para prevenir infecção transfusional pelo Trypanosoma cruzi. Revista da Sociedade Brasileira de Medicina Tropical 29:613-614, 1996.

2. Amato Neto V, Sant'Ana EJ, Pinto PLS, Moreira AAB, Duarte MIS, Campos R. Estudo experimental sobre a possibilidade de prevenção da malária póstransfusional, através do uso da violeta de genciana. Revista de Saúde Pública 21:447-500, 1987.

3. Carter R, Diggs CL. Plasmodia of rodents. In: Kreir JP (ed) Parasitic Protozoa. Academic Press, New York, vol. 3, p. 359-465, 1977.

4. Hamerschalak N, Pasternak J. Doenças transmissíveis por transfusão. Organização Andrei Editora, São Paulo, 1991.

5. Johnson B, Brown JH, Yoedino R, Sikes RK, Santoro J, Cynwyd B, Dahlke M, Hays CW. Transfusion malária: serologic identification of infected donors Pensylvania, Georgia. MMWR 32:222-229, 1983.
6. Schilsky RL. Biochemical pharmacology of chemotherapy drugs used as radiation enhancers. Seminars in Oncology 9:2-7, 1992.

7. Takeda GKF, Campos R, Kieffer J, Moreira AAB, Amato Neto, Castilho VLP, Pinto PLS, Duarte MIS. Ação de raios gama sobre formas sanguícolas de Trypanosoma cruzi. Estudo experimental em camundongos. Revista do Instituto de Medicina Tropical de São Paulo 28:15-18, 1986.

8. Yang SL, Di Santi SM, Amato Neto V, Moreira AAB, Pinto PLS, Boulos M, Campos R, Sant'Ana EJ, Shiroma M. Ação in vitro, da violeta de genciana sobre formas evolutivas do Plasmodium falciparum. Revista do Instituto de Medicina Tropical de São Paulo 30: 17-20, 1988.

9. Walker $\mathrm{RH}$ (ed) Technical Manual. American Association of Blood Banks, 11th edition. Bethesda, 1993. 